\title{
SOBRE O DESENVOLVIMENTO DA LINGUAGEM DE GÊMEOS MONOZIGÓTICOS
}

\section{Development of language in monozygotic twins}

\author{
Naraí Lopez Barbetta ${ }^{(1)}$, Ivone Panhoca ${ }^{(2)}$, Maria de Lurdes Zanolli ${ }^{(3)}$
}

\section{RESUMO}

Objetivo: analisar o relato dos familiares sobre o desenvolvimento dos filhos gêmeos, desde o momento da descoberta de uma gestação gemelar monozigótica, à procura de indícios dos fatores interacionais e sua relação com a linguagem. Métodos: trata-se de um estudo naturalista observacional e os dados foram coletados por meio de entrevistas semi-estruturadas realizadas com nove famílias de gêmeos monozigóticos, durante 30 meses. A análise dos dados orientou-se pelo paradigma indiciário e pelos preceitos da perspectiva histórico-cultural. Resultados: sete famílias relataram um desenvolvimento diferenciado de linguagem, mas não foi ressaltado de maneira tão relevante a ponto de causar preocupação na família. Conclusão: no discurso das famílias, a gemelaridade pode trazer implícita a idéia de que o desenvolvimento das crianças não segue o esperado, já que a própria condição de ser gêmeo não é esperada.

DESCRITORES: Gêmeos Monozigóticos; Linguagem Infantil; Características Culturais; Genética; Relações Familiares

\section{INTRODUÇÃO}

Estudos sobre gêmeos, principalmente os monozigóticos, têm sido usados como modelo, por diversas vezes, questionando sobre o lugar e a importância que ocupam os fatores como carga genética e influência ambiental.

(1) Fonoaudióloga; Professora do Curso de Fonoaudiologia do Centro Universitário Nossa Senhora do Patrocínio de Itu e do CEFAC - Saúde e Educação, São Paulo, SP; Mestre em Saúde da Criança e do Adolescente pela Faculdade de Ciências Médicas da Universidade Estadual de Campinas; Doutora em Saúde da Criança e do Adolescente pela Faculdade de Ciências Médicas da Universidade Estadual de Campinas.

(2) Fonoaudióloga; Professora da Faculdade de Fonoaudiologia da Pontifícia Universidade Católica de Campinas, PUCCAMP, Campinas, SP; Professora Visitante do Programa de Pós Graduação Saúde da Criança e do Adolescente da Faculdade de Ciências Médicas da Universidade Estadual de Campinas, UNICAMP, Campinas, SP; Mestre em Linguística e Doutora em Ciências pelo Instituto de Estudos da Linguagem da Universidade Estadual de Campinas.

(3) Médica Pediatra e Sanitarista; Professora Doutora do Departamento de Pediatria da Faculdade de Ciências Médicas da Universidade Estadual de Campinas, UNICAMP, Campinas, SP; Mestre em Medicina na área de Saúde Coletiva pela Universidade Estadual de Campinas; Doutora em Pediatria pela Faculdade de Ciências Médicas da Universidade Estadual de Campinas.

Conflito de interesse: inexistente
Mas a ampliação de estudos voltados ao controle genético tem deixado claro que qualquer particularidade de comportamento decorre, ao mesmo tempo, tanto de efeitos dos genes, quanto de fatores ambientais ${ }^{1}$.

Gêmeos monozigóticos (MZ) além de possuírem a mesma carga genética, também acabam sendo tratados de modo semelhante. Trata-se do efeito indireto dos genes. Crianças com características genéticas particulares provocam reações típicas nos familiares e pessoas próximas, levando a um resultado associativo entre o efeito direto e indireto do traço genético, o que sugere que as diferenças entre os gêmeos idênticos podem ser atribuídas a efeitos ambientais ${ }^{2}$.

Os gêmeos MZ podem apresentar um desenvolvimento normal, mas muitas dessas crianças, também, mostram um atraso na aquisição da linguagem oral como forma efetiva de comunicação ${ }^{3}$.

Um dos primeiros estudos sistemáticos de desenvolvimento de linguagem em gêmeos utilizou algumas medidas como extensão de sentenças, complexidade gramatical e vocabulário para comparação das crianças ${ }^{4}$.

Pesquisas subsequentes afirmaram que os gêmeos $M Z$ apresentavam um déficit no seu desenvolvimento de linguagem quando comparados a 
crianças únicas e, as prováveis causas investigadas para este quadro mostraram a interferência de aspectos biológicos e, muito mais, de aspectos interacionais ${ }^{5-16}$.

Por fatores biológicos entendem-se as intercorrências pré, peri e pós-natais dessas crianças, que podem ser consideradas como fatores de risco para possíveis alterações de desenvolvimento, tais como: prematuridade, baixo peso e baixa estatura ao nascer, índice de Apgar baixo, alta taxa de mortalidade perinatal, entre outros ${ }^{5-9}$.

Com relação aos fatores interacionais, vários estudos, conduzidos desde a década de 70, apontam a própria condição gemelar como um dos aspectos principais para um atraso na aquisição da linguagem ${ }^{9-16}$.

Esta situação gemelar seria a condição em que as experiências dos irmãos são partilhadas de maneira íntima e especial, criando um padrão diferenciado de circunstâncias interpessoais que podem influenciar a aquisição/desenvolvimento da linguagem. Dessa forma, a condição de gêmeos não criaria uma necessidade "objetiva" de interação linguística com outros, podendo conduzir a um processo atípico de desenvolvimento de linguagem ${ }^{3}$.

Nessa linha de raciocínio, os gêmeos seriam um par auto-suficiente e disso adviria, também, um hipodesenvolvimento em todos os aspectos da atividade mental que dependem da aquisição plena da fala, pois, a uma linguagem "primitiva", corresponderia também um funcionamento "primitivo" das atividades mentais ${ }^{17}$.

Como características/causas dessa condição atípica, têm-se: a-) a falta de motivação pessoal para uma comunicação explícita; b-) oportunidades reduzidas de interação com a mãe; c-) presença de competição durante o processo de comunicação; d-) dificuldade no estabelecimento de identidade pessoal; e-) o aparecimento de linguagem autônoma; $f-$ ) o fato de a mãe não dirigir a fala diretamente para um filho ou outro; g-) um tempo de estimulação menor - teoricamente metade do tempo que a mãe dirigiria a uma criança não gêmea - devido à sobrecarga de atividades pós-natais ${ }^{3}$.

Dessa maneira, o ambiente pós-natal e o padrão de interação familiar associado à situação gemelar seriam os responsáveis pelo atraso na fala ${ }^{15}$.

Em relação a essa linguagem característica de gêmeos, outros estudos falam não propriamente em uma "linguagem autônoma" 3,14, mas sim em uma persistência de formas imaturas de fala ${ }^{17}$.

Dados importantes quanto a esse tipo de linguagem foram pesquisados e, assim, dois subtipos de linguagem secreta foram identificados: a) a de compreensão partilhada que seria uma fala dirigida a todos, mas ininteligível, apesar de ser, apa- rentemente, compreendida pelo par de gêmeos; b) a linguagem secreta dirigida exclusivamente ao outro irmão que seria ininteligível aos pais, mas, claramente compreendida e usada somente pelas crianças gêmeas. Na maioria dos casos, parece ser um fenômeno relacionado ao desenvolvimento durante o segundo ano de vida, juntamente com o surgimento de uma fala imatura, mas que tende a diminuir consideravelmente nos 16 meses seguintes ${ }^{18,19}$.

Por outro lado, o desenvolvimento de linguagem não compreende somente a "competência gramatical", ou aspectos fonético-fonológicos e sintáticosemânticos da língua, mas também a "competência pragmática", ou aspectos pragmático-discursivos da língua. É necessário que as crianças façam uso de uma linguagem apropriada aos diferentes contextos e interlocutores e aprendam como usá-la com o propósito de comunicação ${ }^{20,21}$.

A aquisição destas regras requer uma interação dos conhecimentos linguístico, cognitivo e social que ocorrem desde antes do momento do nascimento.

A produção da vida é um fato cultural de grandes consequências. Antes mesmo que ela ocorra, o futuro ser já faz parte do universo cultural de um determinado grupo familiar e é um acontecimento cujas repercussões sociais não deixam seus autores indiferentes ${ }^{22,23}$.

A linguagem, como produto histórico, tem um lugar especial na comunicação coletiva e grupal. Ela é constitutiva da atividade mental humana, sendo, ao mesmo tempo, um processo social e pessoal que tem origem e se realiza nas relações entre indivíduos organizados socialmente; é um meio de comunicação entre eles, mas, acima de tudo constitui as possibilidades de reflexão, a compreensão e a elaboração das próprias experiências e a consciência de nós mesmos ${ }^{23,24}$

Estudos comprovam a forte influência do grupo familiar sobre o desenvolvimento da criança ${ }^{23-26}$. Desde o nascimento, a criança está em constante interação com os adultos, que compartilham com ela seus modos de viver, de agir, de dizer e de pensar, integrando-a aos significados que foram sendo produzidos e acumulados historicamente. As atividades que ela realiza, interpretada pelos adultos, adquirem significado no sistema de comportamento social do grupo a que pertence ${ }^{27,28}$.

O objetivo deste trabalho foi analisar o relato dos familiares sobre o desenvolvimento dos filhos gêmeos, desde o momento da descoberta de uma gestação gemelar monozigótica, à procura de indícios dos fatores interacionais e sua relação com a linguagem. 


\section{MÉTODOS}

O termo de consentimento livre e esclarecido foi assinado por todas as famílias participantes.

Trata-se de um estudo naturalista observacional e as entrevistas semi-estruturadas foram realizadas pela própria pesquisadora, na residência de cada família ${ }^{29}$. Giraram em torno de depoimentos de pais e irmãos sobre as vivências familiares desde a revelação da gestação gemelar até o nascimento/ desenvolvimento dos gêmeos, incluindo, aqui, o desenvolvimento da linguagem.

O discurso é capaz de transmitir, por intermédio de um porta-voz, as representações de grupos determinados, em condições históricas, sócio-econômicos e culturais específicas e, ao mesmo tempo, revelar condições estruturais, sistema de valores, normas e símbolos. Dessa forma, em pesquisa qualitativa, o discurso configura-se como importante "fonte" de análise ${ }^{30}$.

Neste estudo, os dados longitudinais provêm de oito entrevistas realizadas com cada família participante. A primeira ocorreu no momento do diagnóstico da gestação gemelar monozigótica, a segunda logo após o nascimento e as demais ocorreram em intervalos estimados de três meses, até aproximadamente o $26^{\circ}$ mês de vida das crianças. O intervalo de três meses entre cada uma das entrevistas tinha o objetivo de facilitar o acompanhamento do desenvolvimento das crianças em fases importantes do processo de aquisição de linguagem e da formação da identidade.

Em todas as entrevistas realizadas, os diálogos foram simétricos, ou seja, os participantes têm o mesmo direito à escolha da palavra, tema e tempo para falar ${ }^{31}$.

Além da filmagem, as entrevistas foram transcritas ortograficamente para posterior seleção dos episódios a serem analisados.

\section{a) Dados dos sujeitos}

Dados do Sistema de Informações de Nascidos Vivos (SINASC) ${ }^{32}$ mostraram que, em Campinas, na classificação quanto ao tipo de gravidez, de um total de 13.659 nascimentos, 255 foram duplas.

Assim, considerando-se o caráter qualitativo da pesquisa, para compor o corpus desta pesquisa, incluiu-se inicialmente 10 famílias $(F)$, a partir da fase gestacional, as quais foram selecionadas a partir de registros de acompanhamento pré-natal de dois hospitais da região de Campinas. Esse número de famílias foi determinado de acordo com o critério de saturação ${ }^{30}$.

Todas as famílias estudadas, necessariamente, teriam de ter, em sua composição direta, um par de gêmeos idênticos, sendo este o fator de inclu- são determinante. Os demais fatores, inerentes a um grupo, tais como: diferenças de idade, condição sócio-econômica-cultural, local de domicílio, raça e crença religiosa favoreceram a heterogeneidade das famílias, o que foi considerado um aspecto positivo no corpus, por se aproximar da condição real de diversidade, presente em qualquer grupo social.

A família F3 foi excluída desta pesquisa, pois aos 10 meses de vida, um dos gêmeos foi submetido a uma traqueostomia, o que alterou e retardou, a partir daí, seu desenvolvimento. Então, analisouse, aqui, os relatos de 9 famílias.

Nenhuma das crianças apresentava, inicialmente, outros riscos que pudessem ser determinantes para alterações no seu desenvolvimento.

Das famílias incluídas na pesquisa, todos os genitores frequentaram apenas o ensino fundamental (completo ou não) e oito famílias residiam na periferia da cidade de Campinas, em moradias com pouca infra-estrutura, sem saneamento básico e fizeram o acompanhamento pré-natal e parto pelo Sistema Único de Saúde. Dessa forma, os dados aqui analisados, bem como os resultados encontrados, devem ser entendidos como relativos a essa população estudada.

É importante enfatizar que todos os dados, aqui, são relativos aos relatos de pais/irmãos das crianças gêmeas. Nenhuma delas realizou avaliação formal quanto ao seu desenvolvimento de linguagem.

\section{b) Método de análise de dados}

A análise de dados orientou-se pelos preceitos da perspectiva histórico-cultural que propõe estudar o comportamento em mudança e as condições sociais de produção desta mudança, valorizando seu caráter histórico ${ }^{24}$.

Ainda no campo das abordagens metodológicas, tem-se o paradigma de natureza indiciária, fundamentado na semiótica, como uma perspectiva que conduz à valorização de indícios de processos em andamento ${ }^{33}$.

A partir deste referencial a análise dos dados deu-se de maneira descritiva e orientando-se pelos conceitos propostos na análise da conversação ${ }^{31}$. Como parte do processo de uma pesquisa qualitativa, realizou-se uma pré-análise do material, seguida da seleção de episódios, particularizando o desenvolvimento de linguagem, e posteriormente da exploração e interpretação dos dados ${ }^{30}$.

\section{RESULTADOS}

Em concordância com os referenciais teóricos que norteiam este trabalho, considerando o período da coleta de dados (aproximadamente 30 meses 
com cada família) e a quantidade de episódios/ informações obtidas com base nos relatos dos pais, realizou-se uma análise mostrando aspectos gerais do desenvolvimento de linguagem dos gemelares de todas as famílias (Figura 1) e discutindo-os nos episódios selecionados.
Todas as observações são relativas, principalmente, ao tempo de desenvolvimento (dentro ou fora do esperado) e em algumas famílias houve o apontamento sobre a qualidade da linguagem.

Os resultados estão descritos parcialmente na Figura 1 e, também, entremeados na discussão.

\begin{tabular}{|c|l|}
\hline $\begin{array}{c}\text { Identificação das } \\
\text { famílias }\end{array}$ & Linguagem \\
\hline F1 & $\begin{array}{l}\text { Os pais concordaram que o desenvolvimento estava dentro do esperado, mas, } \\
\text { segundo eles, um dos gêmeos era mais eficiente na fala. }\end{array}$ \\
\hline F2 & $\begin{array}{l}\text { Para a mãe, estava dentro do esperado, mas uma delas, além de falar antes, } \\
\text { expressava-se com mais desenvoltura. }\end{array}$ \\
\hline F4 & $\begin{array}{l}\text { Comunicação pobre. Só falavam quando era necessário. Segundo a mãe, com } \\
12 \text { meses de idade surgiu uma forma de "comunicação secreta" entre eles. }\end{array}$ \\
\hline F5 & $\begin{array}{l}\text { Para a mãe, o desenvolvimento estava dentro do esperado, mas um dos gêmeos } \\
\text { era mais eficiente na fala. }\end{array}$ \\
\hline F6 & $\begin{array}{l}\text { Os pais achavam que o desenvolvimento estava dentro do esperado mas que, às } \\
\text { vezes, falavam de maneira ininteligível, sendo um dos gêmeos mais eficiente na } \\
\text { fala. }\end{array}$ \\
\hline F7 & $\begin{array}{l}\text { Para a mãe, estavam atrasadas e uma das gêmeas era mais eficiente em todos } \\
\text { os níveis de linguagem. }\end{array}$ \\
\hline F8 & \begin{tabular}{l} 
Para a mãe, o desenvolvimento estava dentro do esperado para a idade. \\
\hline F9
\end{tabular} Para a mãe, estava dentro do esperado para a idade. \\
\hline F10 & $\begin{array}{l}\text { Para a mãe, estavam atrasadas para a idade, mas sempre relembrava que } \\
\text { nasceram prematuras. }\end{array}$ \\
\hline
\end{tabular}

* A família F3 foi excluída desta pesquisa, pois aos 10 meses de vida um dos gêmeos foi submetido a uma traqueostomia, o que alterou e retardou, a partir daí, seu desenvolvimento.

Figura 1 - Aspectos gerais do desenvolvimento de linguagem dos gemelares de todas as famílias, com base nos relatos obtidos nas entrevistas

\section{DISCUSSÃO}

Em F1, F2, F5, F6 e F7 as crianças apresentaram, segundo o relato dos pais, até o término da pesquisa, o desenvolvimento de linguagem diferenciado para a idade, pois um dos gêmeos era mais eficiente na oralidade, sendo muitas vezes o portavoz da dupla. Essa observação dos pais pode relacionar-se com uma característica dessa condição atípica de desenvolvimento.

Os achados na literatura corroboram este aspecto, pois confirmam uma alteração no processo de aquisição de linguagem e relacionam tal déficit com um funcionamento aquém do esperado nas atividades mentais $3,17,26$.

Nestas famílias nota-se, também, uma dualidade no discurso da mãe, muito mais do que na fala do pai. Ao mesmo tempo em que a mãe os vê como duas crianças distintas com características diferentes; pelo fato de serem gêmeas idênticas, talvez fique a expectativa de que deveriam funcionar exatamente no mesmo tempo e do mesmo jeito, também na linguagem.

Seriam reações típicas dos familiares provocadas por uma associação entre o efeito direto e indireto do traço genético, muito mais evidentes na mãe ${ }^{2,10,22}$.

Tem-se, então, um aspecto interacional muito forte, visto que, a busca por igualar as crianças aparece com muita intensidade ${ }^{9-16}$.

Por volta de 24 meses, na sétima entrevista, em F1, F2 e F6, as mães se manifestaram quanto ao fato da fala de uma das crianças ser melhor que da outra, evidenciando que, para ela, existe uma diferença, mas também provocando um estranhamento, como se, pelo fato de serem idênticas isso não devesse ocorrer. ( $T$ e os demais sinais serão usados para identificar o turno da conversação e fazer a transcrição das falas ${ }^{31}$ ). 
(F1):

T1 - (mãe): O Daniel fala um pouco mais que $o$ Lucas (+)

T2 - (pesquisadora): E dá para todo mundo entender"

T3 - (mãe): Outras pessoas entendem também(+)

T4 - (pesquisadora): O que que eles falam"

T5 - (mãe): Papai' mamãe' chama o irmão' chama o Bruno' fala o nome do outro' para pedir' fala copo' bala' pede bastante bala (+)

(F2):

T1 - (mãe): A Camile sempre vai primeiro (+) depois a Eduarda (+)

T2 - (mãe): Elas falam cada COISA (+) Falam de tudo e a gente entende tudo (+)

(F6):

T1 - (mãe): O Marcelo é o primeiro' mas falam bastante' do jeito deles' pede bastante coisa' água' bala' banho (+)

Em F4 e F7, os gêmeos apresentaram, de acordo com o relato familiar, um atraso no desenvolvimento de linguagem, mostrando uma comunicação oral ainda pobre, com vocábulos ininteligíveis e só se utilizando a fala quando estritamente necessário ${ }^{3}$.

(F4):

T1 - (mãe): Eles falam bastante' mas' assim (+) na necessidade' abi' solta' dá' não é coisa de ficar falando uma frase direto assim (+)

(F7):

T1 - (mãe): A Julia fala pouco' a Juliane brinca mais de faz de conta' mais quieta $(+)$

Em F10, as crianças apresentaram, para a mãe, um atraso significativo no desenvolvimento de linguagem, sendo para ela, devido ao fato de serem prematuras.

É importante destacar o papel dos aspectos biológicos como fatores de risco para possíveis alterações no desenvolvimento da criança, sendo que a prematuridade, neste caso, pode estar relacionada ao contexto interacional levando a uma alteração de linguagem importante ${ }^{5-9}$.

$O$ aspecto da linguagem foi um dos indicadores presentes no discurso familiar quando questionados sobre o desenvolvimento das crianças, mas não foi ressaltado de maneira tão relevante a ponto de causar preocupação quando não ocorre de maneira esperada.
Parece que a família direta passa a funcionar, então, baseada nos pressupostos sociais atrelados à condição de "ter filhos gêmeos idênticos" ${ }^{25}$.

Por pressupostos ou práticas sociais entendemse as mais variadas formas, socialmente instituídas ou consagradas pela tradição cultural, de pensar, de falar e de agir das pessoas que integram uma determinada formação social ${ }^{23}$.

No contexto de gemelaridade, tais práticas incluem a escolha por roupas iguais ou diferentes somente na cor, a opção por nomes foneticamente semelhantes e estabelecimento de rotinas parecidas quanto à alimentação e sono. Estes hábitos, frequentemente observados no ambiente familiar são, ainda, reforçados nas relações sociais de vizinhança, compadrio e amizade e parecem acompanhar todo o processo de concepção, nascimento e desenvolvimento dos gêmeos, principalmente quando são monozigóticos 10,11,22,25-28.

Aqui, então, pode-se relacionar essas diferenças com o aspecto das contingências sociais distintas interferindo no desenvolvimento de linguagem dos gêmeos ${ }^{3,26}$.

Os depoimentos de F8 e F9 não destacaram problemas de linguagem com os gêmeos.

F4 relatou a presença de uma linguagem secreta entre as crianças (por volta de doze meses de idade), caracterizada, principalmente, por uma oralidade repleta de turnos inintelegíveis, mas que provocava respostas por parte de co-irmão gêmeo.

(F4):

T1 - (mãe): Eles conversam entre eles'

T2 - (pesquisadora): E dá para entender"

T3 - (pai): Não (+)

A linguagem secreta ou criptofasia ou idioglossia costuma ser encontrada em grande escala entre as crianças gêmeas e consiste numa forma de comunicação própria, que pode se manifestar através de códigos verbais ou não verbais, verificando-se, nas crianças que a possuem, enorme auto-suficiência ${ }^{3,14,19}$.

Vale destacar que nem todas as famílias mostravam ter uma atenção mais acurada para o desenvolvimento dos gêmeos, pois a sobrecarga de atividades, principalmente da mãe, fazia com que a família dispensasse um tempo limitado a cada um dos gêmeos ${ }^{3,27-28}$.

\section{CONCLUSÃO}

O acompanhamento longitudinal dessas crianças, até aproximadamente o 26‥ mês de vida, favoreceu a observação da interação intrafamiliar e possibilitou um olhar direcionado ao 
processo como um todo e não somente ao dado isoladamente.

Observaram-se características peculiares quanto à quantidade e qualidade na linguagem dessas crianças, tais como: um dos gêmeos ser o porta-voz da dupla e seu co-irmão ter uma fala pobre, o atraso na aquisição de linguagem de ambos, a presença da "linguagem secreta" e uma linguagem primitiva de ambas as crianças.

Somado a estes aspectos, tem-se a dualidade da mãe que buscando suprir as necessi- dades físicas e emocionais das crianças, é, na maioria das vezes, a única capaz de identificar, diferenciar e anunciar aos familiares a identidade de cada um dos gêmeos e, por outro lado, também espera uma semelhança, na fala de ambos, que reforce e confirme o fato de serem gêmeos idênticos.

Talvez a própria gemelaridade traga implícita a idéia de que o desenvolvimento das crianças não segue o esperado, já que a condição especial de ser gêmeo não é prevista numa gestação.

\section{ABSTRACT}

Purpose: to analyze the report of the families on the development of their monozygotic twins since the acknowledge of twin pregnancy, and describe the environmental factors, as well as their relationship with language. Methods: the study is based on naturalist/observational approach and the data were collected through semi structured interviews with nine families who had a pair of monozygotic twins, during thirty months. Data analysis was performed by using historic-cultural perspective and indicative paradigm. Results: seven families described a differentiated language development, but it was not stressed out in such a relevant manner to the point of causing concern to these families. Conclusion: twinning may bring out the idea that the development of these children do not follow the expected, once that twin children are also not expected.

KEYWORDS: Twins Monozygotic; Child Language; Cultural Characteristics; Genetics; Family Relations

\section{REFERÊNCIAS}

1. Bussab VSR. Fatores hereditários e ambientais no desenvolvimento: a adoção de uma perspectiva interacionista. Psicol Reflex Crit. 2000; 13(2):233-43.

2. Harris JR. No two alike: human nature and human individuality. Twin Res Human Genetics. 2006; 9(5):703-4.

3. Mogford-Bevan K. Developmental language impairments with complex origins: learning from twins and multiple birth children. Folia Phoniatr Logop. 2000; 52(1-3):74-82.

4. Day EJ. The development of language in twins. Child Develop. 1932; 3:298-316.

5. Ishii C, Miranda CS, Isotani SM, Perissinoto J. Caracterização de comportamentos linguísticos de crianças nascidas prematuras aos quatro anos de idade. Rev CEFAC. 2006; 8(2):147-54.

6. Ferreira I, Laureano C, Branco M, Nordeste A, Fonseca M, Pinheiro A, et al. Corionicidade e complicações perinatais. Acta Med Port. 2005; 18:183-8.

7. Kovas Y, Hayiou-Thomas ME, Oliver B, Dale PS, Bishop DVM, Plomin R. Genetic influences in different aspects of language development: the etiology of language skills in 4.5-year-old twins. Child Develop. 2005; 76(3):632-51.

8. Weber DE, Vares MA, Mota HB, Keske-Soares M. Desenvolvimento do sistema fonológico de gêmeos monozigóticos com desvio fonológico: correlação a fatores genéticos e ambientais. Rev CEFAC. 2007; 9(1):32-9.

9. Knafo A, Plomin R. Parental discipline and affection and children's prosocial behavior: genetic and environmental links. J Personal Social Psychol. 2005; 90(1):147-64.

10. Bacon K. 'It's good to be different': parent and child negotiations of 'twin' identity. Twin Res Human Genetics. 2006; 9(1):141-7.

11. Barbetta NL, Panhoca I, Zanolli ML. Aspectos fonoaudiológicos e pediátricos na linguagem de gêmeos monozigóticos. Rev Paul Pediatr. 2008; 26(3):265-70.

12. Campos CF, Pádua ACP, Cruz MS, Hage SRV. Alteração de linguagem em gêmeos: relato de caso. Salusvita. 2004; 23(93):513-30.

13. Zanini RS. Maturidade mental em gêmeos univitelinos. Rev Neurocienc. 2008; in press. 
14. Bakker P. Autonomous languages of twins. Acta Genet Med Gemellol (Roma). 1987; 36(2):233-8.

15. Lewis BA, Thompson LA. A study of developmental speech and language disorders in twins. J Speech Hear Res. 1992; 35(5):1086-94.

16. Dodd B, McEvoyS. Twin language or phonological disorder? J Child Lang. 1994; 21(2):273-89.

17. Luria AR, Yudovich FI. Linguagem e desenvolvimento intelectual na criança. 2. ed. Porto Alegre: Artes Médicas; 1987.

18. Bishop DVM, Bishop SJ. "Twin language": a risk factor for language impairment? J Speech Lang Hear Res. 1998; 41(1):150-60.

19. Thorpe K, Greenwood R, Eivers A, Rutter M. Prevalence and developmental course of 'secret language'. Int J Lang Commun Disord. 2001; 36(1):43-62.

20. Alves TE, Franco KEVB, Hage SRV. Habilidades conversacionais de crianças gêmeas: influência da encefalopatia bilirrubínica. Rev CEFAC. 2004; 6(3):253-8.

21. Wertzner HF, Ramos AC, Amaro L. Índices fonológicos aplicados ao desenvolvimento fonológico típico e ao transtorno fonológico. Rev Soc Bras Fonoaudiol. 2004; 9(4):199-203.

22. Marques ISMAB. Gêmeos: semelhança revelada. Pulsional Rev Psicanál. 2006; 19(185):26-34.

23. Pino A. As marcas do humano: às origens da constituição cultural da criança na perspectiva de Lev S. Vigotski. São Paulo: Cortez; 2005. 303p.
24. Vygotsky LS. A formação social da mente. São Paulo: Martins Fontes; 1989. 191p.

25. Dilalla LF. Social development of twins. Twin Res Human Genetics. 2006; 9(1):95-102.

26. McEwen $F$, Happé $F$, Bolton $P$, Rijsdijk $F$, Ronald A, Dworzynski K, et al. Origins of individual differences in imitation: links with language, pretend play, and socially insightfull behavior in two-year-old twins. Child Develop. 2007; 78(2):474-92.

27. Barbetta NL, Panhoca I, Zanolli ML. Gêmeos monozigóticos: revelações do discurso familiar. Rev Soc Bras Fonoaudiol. 2008; 13(3):267-71.

28. Feldman R, Eidelman Al. Parent-infant synchrony and the social-emotional development of triplets. Develop Psychol. 2004; 40(6):1133-47.

29. Turato ER. Métodos qualitativos e quantitativos na área da saúde: definições, diferenças e seus objetos de pesquisa. Rev Saúde Pública. 2005; 39(3):507-14.

30. Minayo CS. Desafio do conhecimento: pesquisa qualitativa em saúde. 9. ed. São Paulo: Hucitec; 2006. 406p.

31. Marcuschi LA. Análise da conversação. São Paulo: Ática; 2005. 94p.

32. Secretaria Municipal de Saúde - Campinas. Dados do SINASC de mães residentes em Campinas, SP; 2002.

33. Ginzburg C. Mitos, emblemas, sinais: morfologia e história. São Paulo: Companhia das Letras; 2003. 288p.

DOI: 10.1590 / S1516-18462009005000028

RECEBIDO EM: 26/03/2008

ACEITO EM: 08/08/2008

Endereço para correspondência:

Naraí Lopez Barbetta

Rua Izabel Negrão Bertotti, 141 ap. 81

Campinas - SP

CEP: $13087-508$

E-mail: wnbarbetta@terra.com.br 